\title{
USING UX/UI DESIGN TO INCREASE DOG ADOPTION AWARENESS
}

\author{
by \\ Joanna Tsai \\ B.A. Photography, Sheridan College, 2018 \\ Diploma, Media Foundation, Humber College, 2014
}

\begin{abstract}
A Major Research Paper
presented to Ryerson University

in partial fulfillment of the requirements for the degree of Master of Digital Media

in the Yeates School of Graduate Studies

Ryerson University.
\end{abstract}

Toronto, Ontario, Canada, 2019

(C) Joanna Tsai, 2019 


\section{AUTHOR'S DECLARATION FOR ELECTRONIC SUBMISSION OF A MRP}

I hereby declare that I am the sole author of this MRP. This is a true copy of the MRP, including any required final revisions.

I authorize Ryerson University to lend this MRP to other institutions or individuals for the purpose of scholarly research.

I further authorize Ryerson University to reproduce this MRP by photocopying or by other means, in total or in part, at the request of other institutions or individuals for the purpose of scholarly research.

I understand that my MRP may be made electronically available to the public. 


\title{
USING UX/UI DESIGN THEORY TO INCREASE DOG ADOPTION AWARENESS
}

\author{
Joanna Tsai \\ Master of Digital Media
}

Ryerson University, 2019

\begin{abstract}
My project explores the uses of new techniques, colour theories and user interaction design, experimentally deployed through an app experience. Following the theories of $\mathrm{X}$, and by way of example through a low fidelity app prototype, this minimal viable product attempts to address current UI/UX theories and methodologies, while at the same time, trying to address new modes of interface design and user interaction.
\end{abstract}




\section{ACKNOWLEDGEMENTS}

To my parents who raised me to believe in what I want to believe in. Who have let me make my own path in life even when it wasn't what others expected of me.

To my best friends, you all know who you are; your encouragement and faith in me has kept me going, along with a lot of bubble tea and food. For being my stress relief when I needed it, and making me work when I needed it. A special thanks to N.B for helping realize this program was the best choice that I needed to make.

To the friends I've made in MDM who have been the support system I didn't know I needed. I know cohort 6.0 will go on to explore amazing things.

And to my Taffy, the best doggo a girl could ever have; without you I never would've begun this project. It is because of you that I pushed myself to learn more about adoption and rescue and let it become something that means so much to me.

Many thanks to everyone who has supported me throughout this program and project. To all the professors at Ryerson, and MDM staff; your time and dedication towards this cohort has opened infinite doors. 


\section{TABLE OF CONTENTS}

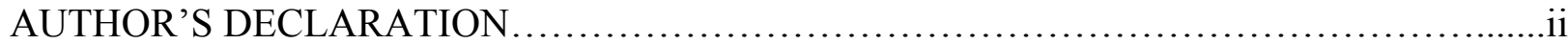

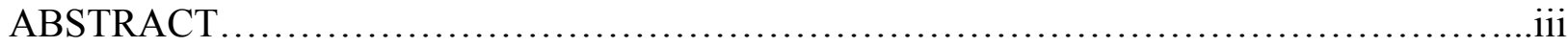

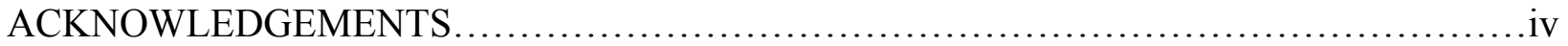

1. INTRODUCTION ................................................................

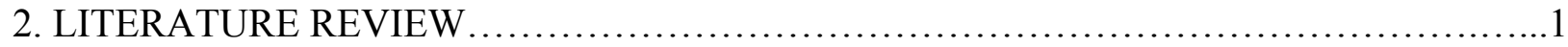

2.1 All About the User.......................................................... 1

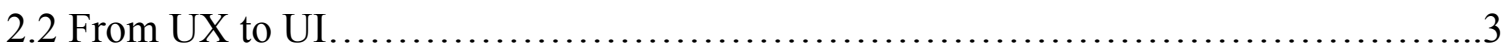

2.3 Why a Mobile App........................................................ 5

2.4 My Design Process................................................... 7

2.5 Shelter Statistics......................................................... 8

2.6 Breed Selectivity ...................................................

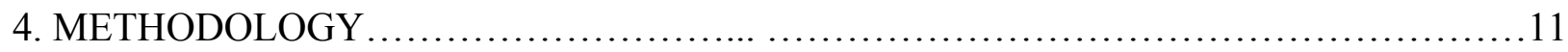

4.1 Gathering Research for Design......................................... 11

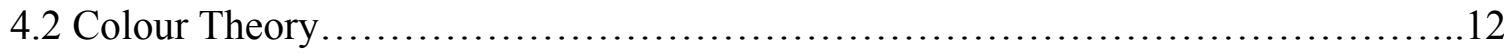

4.3 Icons and Symbols..................................................... 13

4.4 The User's Journey................................................. 14

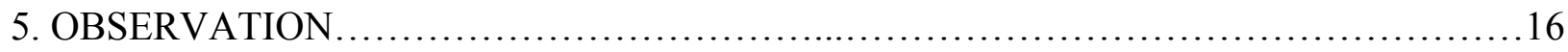

6. CONCLUSIONS.............................................................. 17

7. REFERENCES $\ldots \ldots \ldots \ldots \ldots \ldots \ldots \ldots \ldots \ldots \ldots \ldots \ldots \ldots \ldots \ldots \ldots \ldots \ldots \ldots \ldots \ldots \ldots \ldots, \ldots \ldots \ldots . .19$ 


\section{List of Figures}

Figure 1. Favourite Social Media App Results....................................... 4

Figure 2. Landing Page of Petfinder................................................ 6

Figure 3. Sophie Gamand, Flower Power Series Photograph............................... 10

Figure 4. Screenshot of Current Pawthenticity Prototype Interface......................... 14

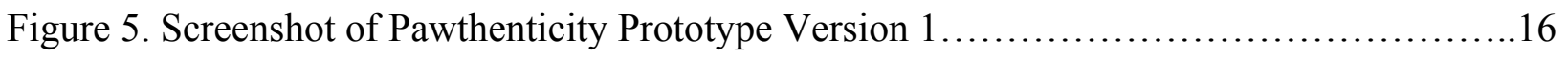




\section{INTRODUCTION}

This project is an exploration of colour, design, interaction and engagement theory as represented by Canziba (2018), Casey (2016), Garrett (2002), McKay (2013), and others, which emphasizes that " $\mathrm{X}$ " can be achieved in user interaction, if " $Y$ " is combined in a thoughtful user design. Although I use an app design as a mode to explore these impactful and relevant concepts of UI/UX design, it should be apparent that this application can be deployed across many digital and physical platforms and as such, is not limited solely to digital medial deployment. In attempting to demonstrate the combination of these important design elements, a new visual language emerges which addresses the gaps in current app design. Through this project I discuss the process of designing to ensure a user can navigate this app intuitively in the most efficient process.

\section{LITERATURE SURVEY:}

\subsection{All About the User}

In the book "Elements of User Experience, The User-Centered Design for the Web and Beyond" Jesse James Garrett (2010) discusses how although someone may have designed a product for a visual experience, it could still fail to be a satisfactory experience for a user. Often times people design an interface that visually is very appealing, and aesthetically pleasing, but is lacking in functionality. From a business standpoint, it is easy to see where companies are coming from when they add various features into their product; Garret is discussing websites in this particular situation when he says,

Having more features, however, turns out to be only a temporary source of competitive advantage. With the added complexity that comes with an ever-expanding feature set, 
sites become increasingly unwieldly, hard to use, and unappealing to the very firsttimers they are supposed to draw in. (Garret 2010,pg9)

It is with this that I realized that there are infinite variations of how a user can explore a product which in turn can result in varying degrees of success. Leading to the thought of how can I ensure a user does something a certain way so it's the most efficient process? By providing a user with a diverse set of options, it may result in only encouraging a user to diverge from the path of the friendliest user experience. Although this reading was more specifically discussing web design, through my own experiences I have realized that user experience is not limited to just web and mobile, but also products in a tangible sense. Which is why I consider this project as both a digital and physical experience. Although the screen is a mobile experience, the overall process is still a tangible, physical thing. This encouraged me to see beyond my design as just a screen for a user, but a full emotional handheld experience. It is not just about text hierarchy and hamburger menus and icons, but about the physical functions, finger gestures, and usability.

Tony Russell-Rose and Tyler Tate (2013) discuss how to design for a user outside of just their search experience. Through this reading it reminded me that the goal is to display not only what the users want to see and experience, but how they process what they see and how the information displayed is stored. Every user is unique, and in order to market adoption to the largest audience possible, it is essential that I considered the generation we live in now. Many elders are not as tech savvy as millennials and Generation Z, and even some of the Generation X demographic will lack the understanding required to experience the full functionality of a hightech app. Russell-Rose and Tate make an interesting metaphor in this when they compare professional photographers to everyday phone photographers. (2013) While one may prefer a high end DSLR and the other a mobile phone or point and shoot camera; "both novices and 
experts gravitate toward the tools that best match their abilities" (Russell-Rose \& Tate 2013). I

realize that with this notion it is essential to design for learnability, so that whether my user is a tech expert or rookie, they can still progressively become more knowledgeable of the interface and functions and know how to interact with them. Russell-Rose and Tate use "contextual instructions, immersive overlays, and subtle visual design" (2013, pg11) as some key factors in design thinking. I took these factors into consideration when framing my landing page, I wanted there to be a strong visual representation of my brand, while also providing something for the user to engage in and interact with. It required a simplicity to the user's tasks, allowing them to understand how to move forward in the app without needing step by step instructions.

\subsection{From UX to UI}

I had to understand that I was designing for a user to not only navigate and search, but to be able to reach a particular goal. In this case, reaching the adoption application; but there is no guarantee that a user will reach this goal just because it is what I hope for. Instead I designed to optimize this search process using UX to provide the most effortless browsing to get my users as close to the goal as possible. Asking myself questions like, how do I design so that if it is a new user, with no prior knowledge of this app and how it functions, how do I ensure they have a good experience utilizing this app. In comparison, how do I keep returning users engaged and maintain interest in this app when the interface and function remains the same. To figure this out, I conducted my own research by creating an online survey to determine what people's favourite social media apps were. This survey was distributed online using an among 30 people ages 18 to 55 , of primarily female respondents, as only 8 males responded. Ten questions were included in 
this survey; starting with whether the respondent had a dog or not. If a user had a dog they were brought to the next set of questions asking how many dogs they had, and how they got their dog. For the respondents that didn't have a dog, they were asked where they would look to find available dogs. Each respondent was asked if they would ever consider adopting a dog in the future, as well as their favourite colour, and top 2 social media apps.

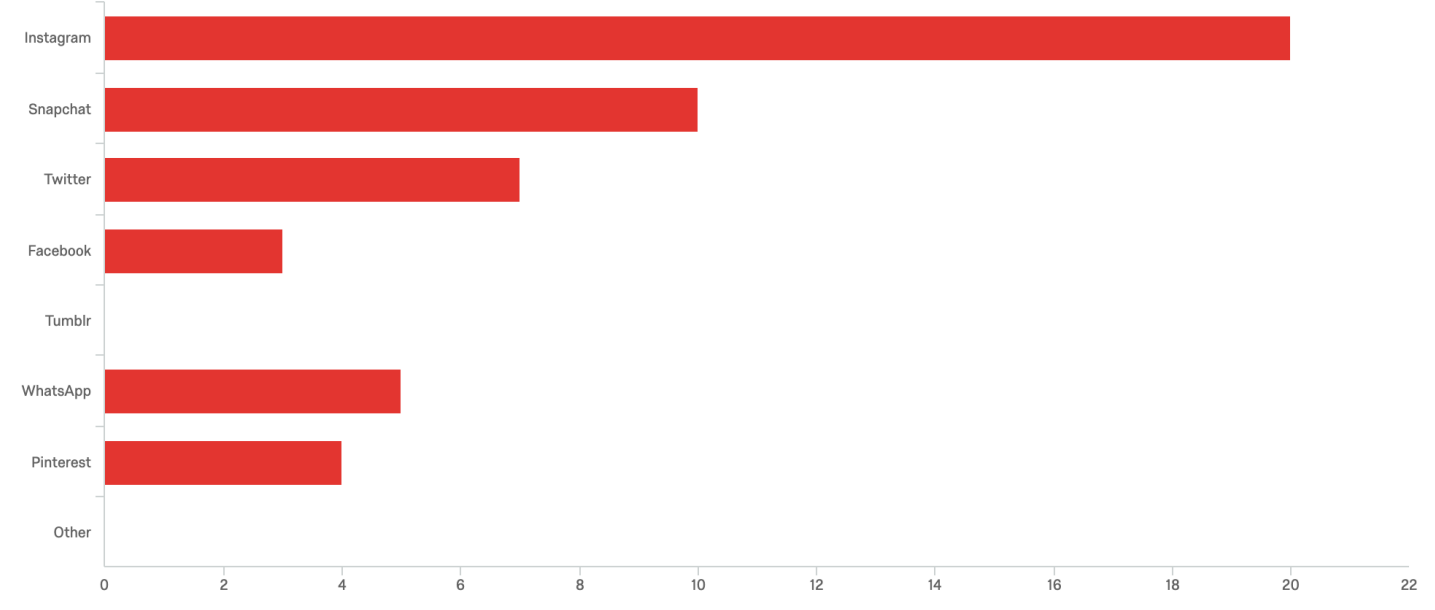

Figure 1 - Favourite Social Media App Results

Among 30 survey respondents, over 70\% of users said Instagram was their favourite app to use, and upon further in person questioning I learned that users love the consistency of it. Every time it's opened up, a user sees the same interface, they are familiar with the functions, and usually have a good general idea of what they want to do on it; they are either sharing content or viewing content. Users find Instagram is a good app to keep going back to because there is consistently new content, there will always be something new to explore, with almost infinite images, videos, and posts to see. Through this research within this group of respondents, 
it has been demonstrated that in order to have reoccurring users, there must be consistent new content for its users, while maintaining effortless usability.

Everett McKay quotes Jan Miksovsky in his book "UI is Communication: How to Design Intuitive, User Centered Interfaces by Focusing on Effective Communication” (2013, pg1); "The moment a user sees your UI, it communicates where they have arrived, what they can do, and how they should do it. The user receives this message from every aspect of your design: graphical and textual, silent and audible, static and moving, intentional and accidental. Figure out what you want that message to be, then do everything you can to ensure the message your UI sends is as close as possible to the one you intended."

This resonates with my research and practical approach to using UX and UI to solve this problem of increasing dog adoptions because I aim to use my knowledge in design theory to create this solution, which is what I hope is communicated across my platform.

"UI is communication" (McKay 2013, pg15). I needed this interface to carry a conversation without using words, my goal was to design this interface so users would know the function of each button and the purpose of each page without question. Every symbol, word and image serves its own purpose and is an essential part of the design. An interesting concept that McKay discusses is how beauty, style and fashion is largely subjective, but an intuitive task or function of a button should not be to a user. (McKay, 2013). This communicated to me that every design decision I make in my UI; from icons, menus, colour, layout, buttons, and more all play a role in conveying a particular message to my user. In having a clear objective communicated through my UI, it minimizes the potential for a user to misunderstand the goal of the product. Each UI element needs to have a purpose, and if it is not meant to communicate anything to the user, it becomes a redundant part of the design. 


\subsection{Why a Mobile App}

For this project, current trends and survey suggested that creating an app would be more successful than a web platform because of the accessibility of mobile devices. In addition to this, the current market for dog adoption is limited to individual social media pages for private rescues, and organizations, and Petfinder being the only larger scale company. With everything being on a separate platform, users lack efficiency in their search to adopt, therefore if there was one universal design which provided an enhanced UX and UI; my expectation would be to see an increase in adoption numbers. Users looking to adopt are of a diverse age range, as people can be looking to adopt a dog at any point in their lives. There is a lack of existing mobile applications that provide a user with the most efficient adoption experience; therefore, my app would represent a much more efficient process regardless of who the user is. The current existing pet adoption platform is Petfinder, however it only functions as a website, although accessible through a mobile internet browser; does have an individual app platform for users. Within this past year, Petfinder underwent a massive brand redesign and website renovation. Creating a much friendlier UI and usable UX, however still lacking in the actual adoption process.

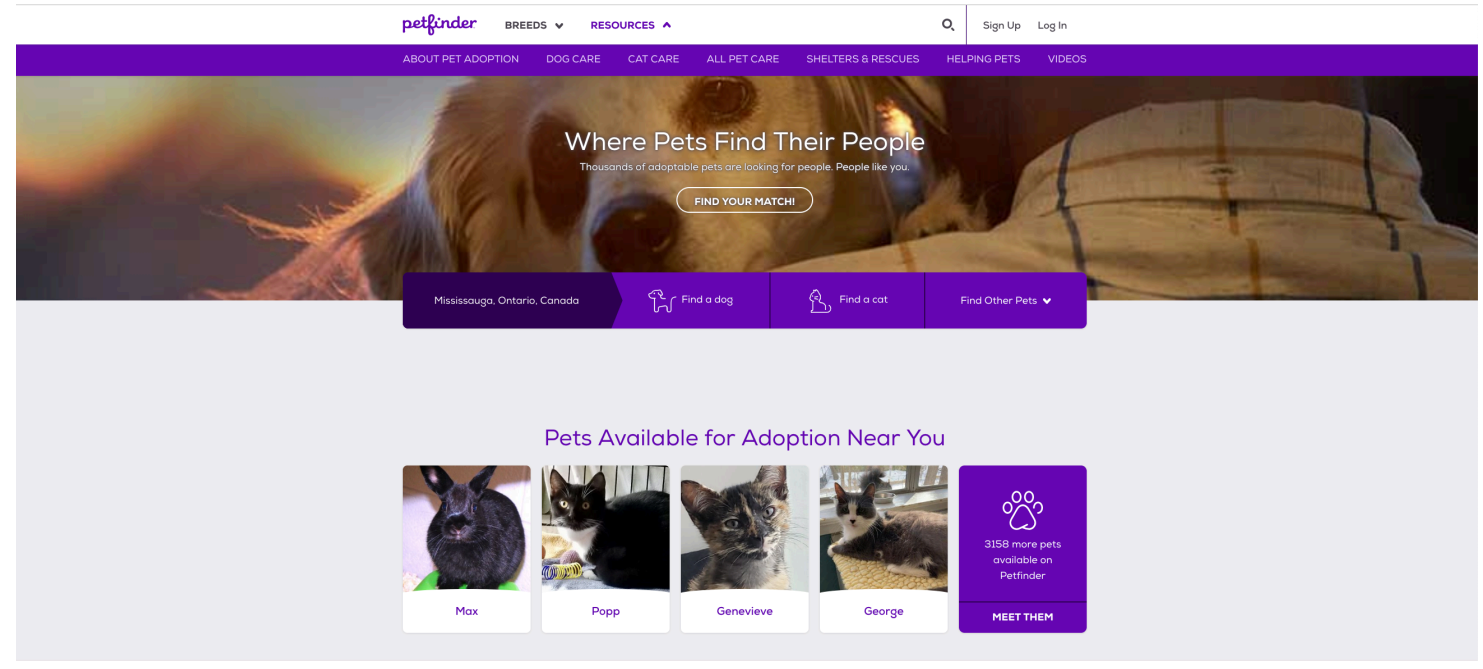

Figure 2 - Landing Page of Petfinder 
As mentioned above, the platform is for web only, but is accessible through a mobile internet browser; however, is not as mobile friendly as it lacks usability. Mobile users will need to navigate the site through extensive scrolling from just the initial home page, and there is a lot of content that it tries to cover. Petfinder also goes beyond just being an adoption platform for dogs, by also showing small rodents, birds, to even farm animals that are available. They also have separate headings for care, breeds, videos, shelters and many more. In a controlled and familiar user group, I asked participants to navigate the site on a mobile device to test functionality and overall design of the website, and out of 10 users, 8 felt overwhelmed by the amount of content on just the first page of the home screen. Although Petfinder offered a diverse group of animals that were available to adopt, one user pointed out that they wished there was more consistency in the photographs of the animals; as they felt this would have created a more visually appealing interface. Another user pointed out that their filter menu offered selections for particular breeds even though there was zero displayed, which they found misleading. In addition, with over 10 options to refine their search; over $50 \%$ of users did not know what to search for, which ties back to Garrett's discussion on how although it is nice to offer so many features and options, it adds a complexity to the experience that just makes it harder to navigate, making it less usable. This served as a reminder to me that it was essential to validate my own opinion of an interface with unique users, as each user navigates differently. Elvis Canziba author of the book Hands-On UX Design for Developers discusses the importance of being able to validate user research and confirming assumptions that I have made about a design (2018). Although this was not in reference to my own design, it allowed me to reiterate the problem and identify the need for a new mobile friendly platform for users. 


\subsection{My Design Process}

When beginning my design process, I referred to the Stanford Design School Thinking Process (Plattner, 2010); empathize, define, ideate, prototype, and test. In the early stages of development, I questioned who this project could benefit, and I was reminded of a friend who went through an extremely strenuous adoption process to find the dog the currently own now. They started off with Petfinder, submitted an application for a dog and it wasn't until almost a week later they received a response that the dog had already been adopted. They then turned to physical locations and visited the Oakville \& Milton Humane Society; they found a dog and fell in love, and proceeded to submit an application that very day. Approximately a week later, it was found that the dog they had submitted an application for was no longer showing as "available" on the humane society's website. After a few weeks of feeling maybe it wasn't the right time to adopt a dog, they were introduced to Niagara Dog Rescue, a non-profit, volunteer based organization that works to finding dogs their forever homes. It was with this rescue that they were able to contact a volunteer directly and submit an application for the dog. Within a few days they were able to bring home their beautiful rescue dog home. It was experiencing my friend's adoption process first hand that I realized why so many people turn to breeders instead. No one looking to find a dog for their home wants to go through weeks of searching, constant follow ups, and phone calls to find out if they can adopt a dog. I knew that one user's struggle to adopt didn't represent the entirety of the adoption market, however it reinforced my idea that if every adoptable dog was on one universal platform, users would have easier access to browsing, as well as a much more manageable way of getting updates about the dog. I contemplated concepts similar to Tinder, where users could get matched up with a dog, as well as a community platform for all things adoption related for events and fundraising. However, after pitching my 
ideas and throwing around potential platforms during presentations in class, I felt strongest about a dog adoption platform that would provide users with the most efficient and successful adoption experience. I received feedback about potential features this app could have, and what people felt would make it more successful; such as having more detailed background stories about the dog, and displaying the costs of owning a dog. After sketching out basic thumbnails and wireframes, I began to build my prototype in Adobe XD. Using Adobe XD, I was able to generate previews of my prototype with would replicate what the overall UX and UI would look like. Through this user testing I was able to continue refining my design and functionality of the prototype before fleshing out the finer details.

\subsection{Shelter Numbers and Statistics}

In 2012, Canadian shelters took in over 11900 cats, 53000 dogs, and 15000 other animals. These numbers only represent 102 shelters who responded to the Canadian Federation of Humane Societies (CFHS) statistics survey (2012) and does not include all humane societies, SPCAs, local shelters and private organizations. On December 18, 2013; the CFHS released the national animal shelter statistics report for the year of 2012, in which Toolika Rastogi, Policy and Research Manager at the CFHS stated that only $26 \%$ of dogs who enter these shelters are reclaimed. Out of these 53000 dogs entering the shelter, only 7\% are already spayed or neutered. With the consistent problem of animal overpopulation, $15 \%$ of dogs in shelters are euthanized. This number is considered a far improvement from the mid-1990s where the euthanasia rates were close to $30 \%$. In 2015 , CHFS reported that adoption rates went up $48 \%$, in the two decades that the organization had been collecting data; this is the highest level. "Shelters are transferring pets to other shelters and rescue organizations as a way to increase adoption" (Casey, 2016). 
In the span of 3 years there was a major increase in dog adoption, and social media plays a major role. When users have a digital platform, it becomes significantly easier to spread the word about a subject. Whether it is for fundraising, or non-profits, social media has become a goto for companies and organizations to connect to their users. By creating an online platform specifically targeted towards dog adoption, users looking for that specific thing will no longer have to rely on various sources of social media, but rather have one direct source.

\subsection{Breed Selectivity}

A large topic of conversation that always comes up when it comes to dogs is breed selectivity. There are always people looking for "purebreds" and specific breeds, people will continue doing it for financial gain; even when it is detrimental to the dog. In September of 2010, the Public Broadcasting Service (PBS), published an article about selective breeding problems and stated "In the same way that inbreeding among human populations can increase the frequency of normally rare genes that cause diseases, the selective breeding that created the hundreds of modern dogs' breeds has put purebred dogs at risk for a large number of health problems, affecting both body and behaviour". Because yes, people always love a golden retriever and corgis and the typical cute dogs that people love to idealize on Instagram, but these viewers lack the understanding of what it means to be a dog owner. Many people get caught up in the appearances of a dog, and don't realize the drastic lifestyle change that may be required when you bring a dog into your home; especially particular breeds that are prone to health problems and regimented routines. I would hope to use my platform also as a way to educate people about this issue, and in turn hoping it would reach a larger audience and change some perceptions. There are people who work tirelessly to end the stigma associated with certain 
breeds. A great example of this is Sophie Gamand, a French photographer who photographs dogs to learn about their relationship with humans, but also dedicates time to advocate for shelter dogs and pit bulls in particular. Her series "Flower Power" focuses on celebrating their personalities and vulnerability that has led to hundreds of dogs to be adopted and find loving homes. By destigmatizing these animals who have been generalized by society as a threat to people; more and more people have put forth efforts for these animals to find forever homes ("Flower Power", n.d.). Her work has helped people to understand that dogs are not born aggressive, and the love they can offer goes beyond their appearance.

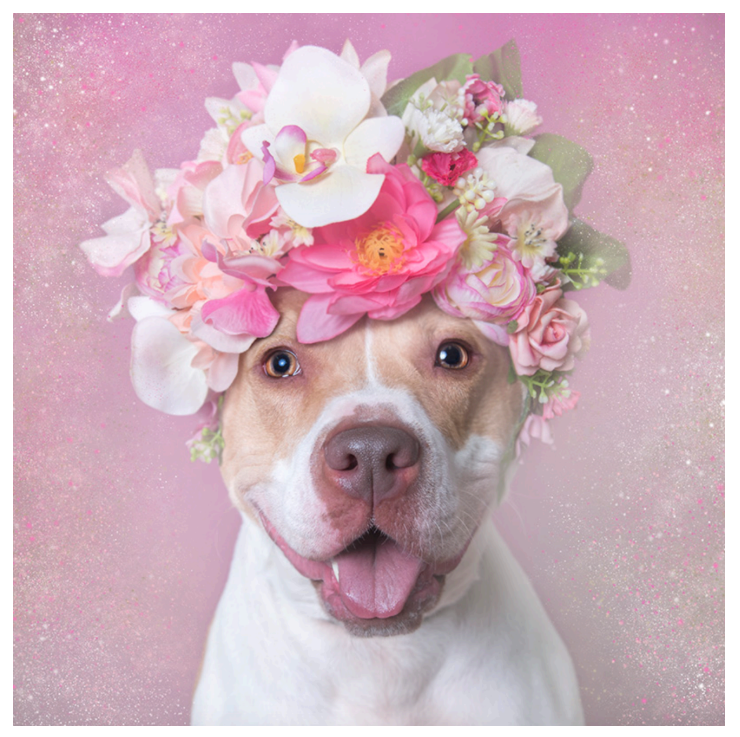

Figure 3 - Sophie Gamand, Flower Power Series Photograph

Gamand's design aesthetics has lent to my overall design theory and heavily influenced me, as I have seen how her photographs have helped to destigmatize these animals in which people have consistently associated with violence. I was introduced to her work in 2014, shortly after she started this series, and since then I have watched her platform grow and see her sharing photos and videos of dog after dog getting rescued and adopted. I think seeing dogs on a beautiful interface, and having a visual experience in the adoption process would a great benefit in marketing adoption as an option for more users. 
When more people are willing to adopt, it takes away the financial incentive for breeders to breed selectively. However, as long there are people looking for "purebreds" and specific breeds, people will continue doing it for financial gain; even when it is detrimental to the dog. "In the same way that inbreeding among human populations can increase the frequency of normally rare genes that cause diseases, the selective breeding that created the hundreds of modern dogs' breeds has put purebred dogs at risk for a large number of health problems, affecting both body and behaviour" ("Dogs That Changed the World | Selective Breeding Problems | Nature | PBS", 2010). Some dogs have been bred to deliberately manipulate their appearances, such as the flat face of a bulldog that leads to breathing problems, the low-slung eyelids of bloodhounds that leads to eye irritation and infection, the wrinkles of a Shar Pei that leads to skin infections and far more. Apart from physical ailments, autoimmune disorders and even neurological problems become issues in pure bred dogs. It is because of these reasons, that I myself worked on a photo series as part of my final thesis project before graduating from my photography program that focused on portraying the diversity of dogs, and what they have to offer. It is for this reason that I hope this app can also function as an educational platform. There is too much sensationalized media that is associated with certain breeds, and in turn can become a deterrent for anyone interested in owning a dog. Similar to Sophie Gamand's approach, I want people to be able to look at these dogs without any pre-existing notion. A platform free of judgement where the only goal is to get dogs into a loving home. Although this is not the only approach that may work to get dogs adopted, it is one that is also on brand for me. As a visual person myself, with a photography background, I have learned about the impact a single image 
can have for representing a cause. Which is why I feel that UX and UI play such a significant role in deploying this platform to address an issue like dog adoption.

\section{METHODOLOGY}

\subsection{Gathering Research for Design}

To design the most effective dog adoption app, a key word that I kept in the forefront of my mind was "effortless". I wanted this app to be accessible to anyone that has ever had a desire to adopt a dog, but didn't have the ability to because the lack of efficiency on another platform. I created an online survey to gather information about my users. This survey was sent out to people of all ages ranging from 18 to 65 , in order to get a diverse pool of results. It was with this survey that I was able to determine what I wanted my brand colour to be, and represent. As well as what the ideal interface would look like for a user to navigate through my prototype successfully.

I developed a prototype for Pawthenticity using Sketch, where users are able to get a general sense of what this app would look like after being fully developed, as well as how the UX would flow. Current users are able to sign up and browse through adoptable dogs, after which they can select a dog to view their profile and story. Should the user feel a connection to this dog they are then able to submit their application directly to the rescue or shelter in hopes of adoption this dog. The entire process could take a user anywhere from 2 minutes to 5 minutes at its current stage of development; which I consider successful, because users will not want to spend an extended amount of time signing up and browsing through an app if they don't see 
anything they like. This way users are able to get a good feel of the UI and how the UX works within minutes before they see a dog.

\subsection{Colour Theory}

In the book "Color Theory and Its Application in Art and Design" George A. Agoston (2013) discusses how colour is an experience, and can convey a psychological meaning; as it acts as a stimulus in the brain. When designing this app, apart from the UX, the interface itself stemmed from a visual concept that projects a welcoming feeling. I felt that using a bright, effervescent colour would be more successful and desirable for a user than a chic, cool tone because I wanted users to open this app and feel excited and welcomed as they start their adopting journey. This lead to me to the decision to use "Living Coral" as the brand colour, the Pantone colour of 2019, as I wanted this interface to represent not only a joyful and exciting experience, but also tying it back to design trend. Because coral is considered as a part of the orange family, it is a colour often left out of design and fashion trends. However, because of the touch of pink it holds, it becomes a much more embracing colour to the user. Living Coral speaks to users as outside of just colour, in the real world it is a vital part of our oceanic ecosystem, one that embraces life and contributes to countless living organisms under the sea. I chose to bring the way Living Coral represents life, to my design because I wanted it represent this new life that dog adoption can bring, bringing it back to the brand ideals. Which is why I felt Living Coral would be the best colour to convey my intentions. 


\subsection{Icons and Symbols}

In a book by BlackCoffee Design “1000 Icons, Symbols, and Pictograms: Visual Communications for Every Language" it is discussed how icons and symbols represent a very pure form of visual communication. "They transcend the boundaries of language and culture to convey a concept quickly and effectively" (2006). Each icon was carefully chosen to ensure usability and functionality. I chose to represent the menu as icons instead of words because it allows for users to rely on a visual representation in comparison to using text. The bottom panel consists of 3 basic icons; a question mark for "help and FAQs", a magnifying glass for "search", and a dog house to represent "home". My decision to use these icons in this manner stems back to my initial research about favourite apps, as the minimal approach to Instagram seems to be the most successful; therefore, I decided to keep the options that my user would have to navigate to a minimum. There is a small arrow on each screen at the top left-hand side indicating the option to go back at whichever screen the user is on. This was a fairly straightforward choice for me to make and I chose a thin arrow within a circle to replicate the visual of the FAQ button almost parallel beneath it. The only other buttons a user will see is the search filter option on the top right-hand side. This button only appears when a user is on the search page for adoptable dogs, enabling them to refine the selection of dogs that appear for them. It consists of three lines with a circle on each line; representing level adjustment, however, in user testing it was determined that this icon was not as straightforward as the others to the average user. Majority of users did not realize that in order to continue searching and refine their search they had to filter their results first. This led to some confusion for users and resulted in them having more difficulty reaching the "goal" of the app. However, the FAQ, Home, Search, and Back button were successful; as all 
users were intuitively able to understand the purpose and intent for them. They were able to communicate its function without needing text. All the buttons are either on the bottom of the screen, or top corners which ensures that a majority of users will be able to utilize these functions one handed, and will not require additional gestures in order to achieve a function.
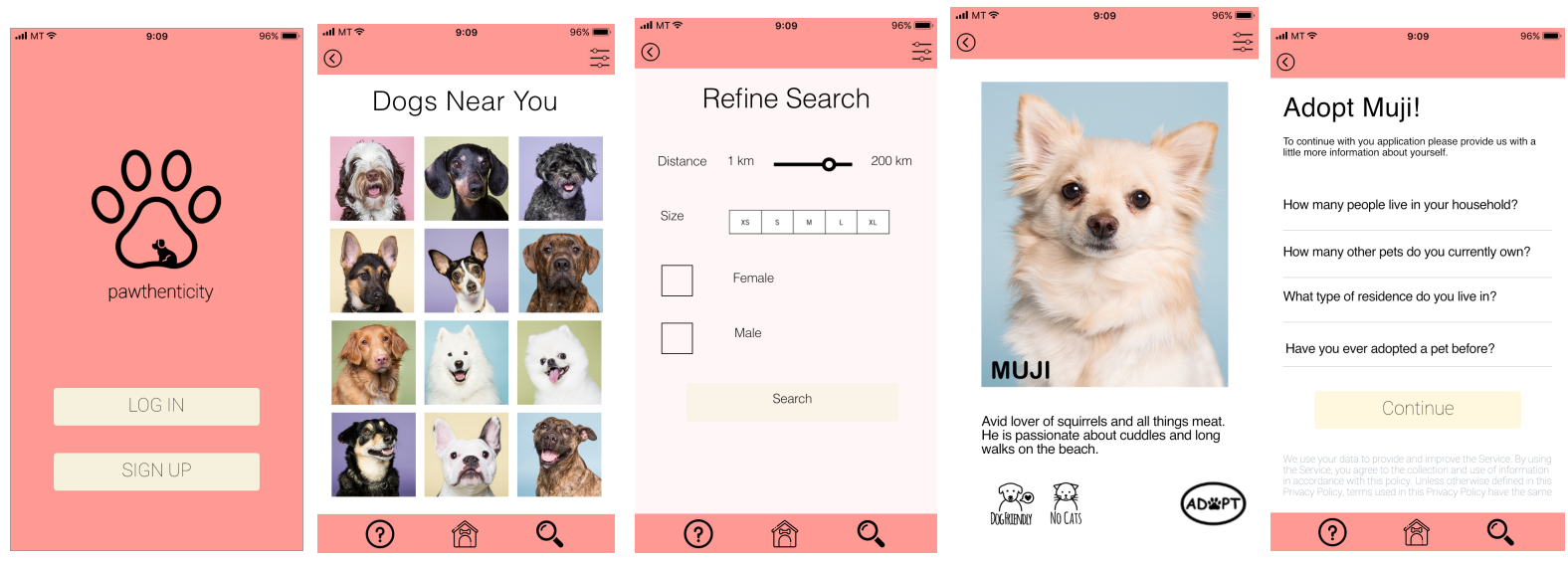

Figure 4 - Screenshot of Current Pawthenticity Prototype Interface

\subsection{The User's Journey}

My user is not defined by gender, age, or income; but they are someone interested in learning, and has the desire to adopt a dog. They could be a new graduate looking for a buddy, or a mother hoping to add to her family. They are someone with stable income to support the extra mouth to feed, and are ready to venture outdoors on more than one occasion in a day for a pee break and walk. The user's journey begins with the launch page, a simple screen with a logo and 2 options; sign up, or login. A new user would sign up by providing basic information such as name, address, email, and phone number. It would take a user under 1 minute to complete this process, and minimizes the need to ask for contact information further down during the adoption application process. I chose to separate all the adoption application questions and the essential 
contact information of a user because in the early stages of user testing, I swiftly realized that users would not be willing to spend more than 5 minutes going through a sign up and application process before they've even seen a photo of a dog. Following the sign-up process, the user is automatically directed to a spread of images of adoptable dogs that is closest to them based on geographic region.

The process of getting from the first screen; the landing page, to the last screen; adoption application, could take less than 2 minutes to reach. I minimized the number of screens, and options for users in order to make this adoption process as efficient for a user as possible. In my user testing, I determined very early on that users did not want to begin their adoption search with a full screen of text asking for contact information, and pet history, and their living situation. Therefore, I made the sign-up process consist of only a name, email, phone number, and address. The user is then directed to a screen populated with adoptable dogs that are closest to them based on geographic region, but will have the option to filter and refine their search, giving the user options like selecting the distance range, the size, and gender. Initially there was over half a dozen other filter options like searching for breed, age, cat friendly, and more, however having too many options resulted in the user journey being more clustered and majority of users became overwhelmed, making the process inefficient. Users are able to tap a dog's photo and be provided with the full image of them, along with some information about the dog. The user is then able to access an adoption application which consists of 4 short answer questions to be submitted to the rescue the dog is being fostered with. During user testing one of the things I kept a lookout for was any indication that the user was no longer engaged in the looking at the prototype, or found it too time consuming. I didn't want users to lose interest if the sign up and adoption process were too long, as any screen that is too text heavy would result in 
users just trying to skim through it. In my user testing process, I noticed users would not bother reading some text, such as the welcome screen with an introduction, as well as the confirmation screen after an application was submitted, which was why I ended up changing the interface in the new prototype. The initial prototype consisted of 3 screens back to back for either the user to fill out or read, so I made the decision to just get all the contact information out of the way when a user signs up for the first time, allowing me to eliminate the screen at the end. This creates a more effective user journey because then the user gets more of a conclusion/goal when they reach the last screen of successfully sending in an adoption application.

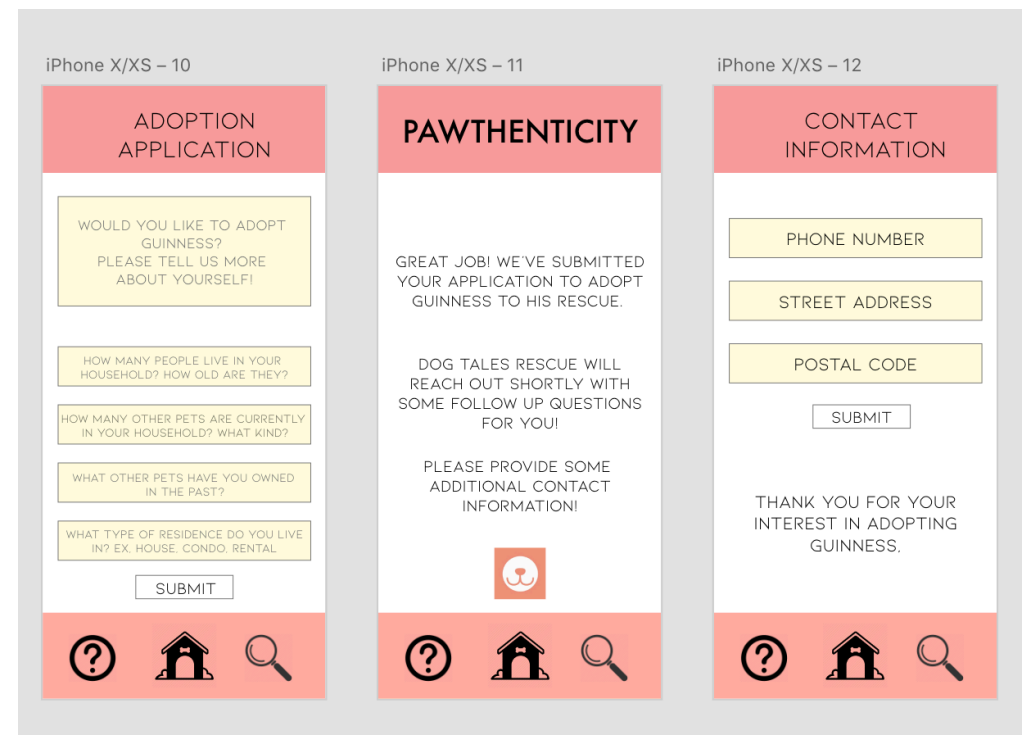

Figure 5 - Screenshot of Pawthenticity Prototype Version 1

\section{OBSERVATION:}

Some recommendations for the future of this project would be to continue user testing, and gather data from a larger pool of surveys. I would like to conduct more interviews on topics aside from the UX and UI discussion and ask about what other content people would want to see 
on this platform. A change that I would make, based on user interaction, is on the dog's profile page. Instead of having a brief description, I think it would be much more successful to attach their story instead. Where did this dog come from, how did they get to this point, and what type of home they are looking for. In addition to this, as discussed in section 4.3, users did not intuitively realize that the option to filter and refine their search results was in the top right corner. As this is a feature that would greatly benefit my users, I would like to change the UI slightly to incorporate it in a way to emphasize it more. Further user testing is required to determine the usability of a revised feature and evaluate its functionality.

I was able to user test after applying my methodology and research of colour theory, icons and symbols, and user journey to the final design. It allowed me to witness from a secondhand perspective how users perceived the app and how it would function. In a controlled environment, I was able to conduct 10 new user tests to evaluate the usability of my new prototype. I determined that the functionality was successful; as every user was able to navigate through the prototype successfully, with the only major change most likely being the filter function. However, over $90 \%$ of user testers were still able to explore the UI intuitively without needing a prompt. The icons and symbols were usable and did not need further explanation. All users were able to reach the final screen of the adoption application efficiently, allowing me to come to the conclusion that UX and UI design can indeed enhance the adoption process.

\section{CONCLUSIONS:}

This project was to explore the possibilities of using UX and UI design theory to enhance the dog adoption process, and evaluate if a more efficient user experience would result in a 
higher adoption rate and increase awareness. When an app is straightforward, efficient, and usable, users will be more inclined to keep using it and share it; which is exactly my goal with this project. Throughout the process of completing this paper I have researched UX and UI design, but also dog adoption and the topics associated with it. With this project, I have had the opportunity to combine a passion project of mine with my studies. From each detail on my prototype comes with an intention, I learned that each symbol, line and colour must have a purpose in my design. A user will not analyze each detail, but will intuitively recognize features and indirect meanings; making it essential that nothing on their screen is a redundant part of the design. More research may be conducted under the circumstances of pursuing a PHD. 


\section{REFERENCES:}

(2006). 1000 Icons, symbols pictograms: visual communication for every language; 1000 works selected by Blackcoffee. Gloucester, MA: Rockport.

(2013). Shelter animal statistics. Retrieved from

https://www.humanecanada.ca/shelter_animal_statistics (2019)

(2014, October 21). Dogs That Changed the World. Retrieved from

https://www.pbs.org/wnet/nature/dogs-that-changed-the-world-selective-breedingproblems/1281/

Agoston, G. A. (1987). Color theory and its application in art and design. Berlin: Springer.

Canziba, E. (2018). Hands-On Ux Design for Developers: Design, Prototype, and Implement Compelling User Experiences from Scratch. Birmingham, UK: Packt Publishing.

Casey, L. (2016, December 22). Adoptions are up, Euthanasia is down at Canadian Animal Shelters, report says. Retrieved from

https://www.thestar.com/news/canada/2016/12/22/adoptions-are-up-euthanasia-is-down-atcanadian-animal-shelters-report-says.html

Gamand, S. (2014.). Flower Power. Retrieved from http://www.sophiegamand.com/flowerpower

Garrett, J. J. (2002). The Elements of user experience: user-centered design for the web. New York: AIGA.

McKay, E. N. (2013). UI is Communication: How to Design Intuitive, User-Centered Interfaces by Focusing on Effective Communication. Amsterdam: Morgan Kaufmann.

Plattner, H. (2010). An Introduction to Design Thinking Process Guide. Retrieved from https://dschool-

old.stanford.edu/sandbox/groups/designresources/wiki/36873/attachments/74b3d/ModeGuideBO OTCAMP2010L.pdf

Russell-Rose, T., \& Tate, T. (2013). Designing the Search Experience: The Information Architecture of Discovery. Amsterdam: Elsevier, Morgan Kaufmann. 